\title{
Activation of the classical complement pathway in spontaneous bacterial peritonitis
}

\author{
G Bird, G Senaldi, M Panos, N Rolando, G Alexander, D Vergani, Roger Williams
}

\begin{abstract}
To investigate the possibility that low complement concentrations in the plasma and ascites of patients with severe liver disease could be secondary to complement consumption, complement activation was studied in 32 patients with severe liver disease, 11 of whom had spontaneous bacterial peritonitis (SBP). In patients with SBP, plasma $\mathrm{C} 3$ and $\mathrm{C} 4$ were significantly lower than in uninfected patients (mean values $0.74 v 1.13 \mathrm{~g} / \mathrm{l}, \mathrm{p}<0.01$ and $0.20 v$ $0.28 \mathrm{~g} / \mathrm{l}, \mathrm{p}<0.05$ respectively). Plasma complement activation via the classical pathway, as shown by $\mathrm{C} 4 \mathrm{~d} / \mathrm{C} 4$, was significantly increased in patients with SBP compared with uninfected patients $(37.3 v 22.2, \mathrm{p}<0.01)$ as was $\mathrm{C} 3 \mathrm{~d} / \mathrm{C} 3$ $(14.0 v 8.11, \mathrm{p}<0.01)$, but there was no significant difference in $\mathrm{Ba} / \mathrm{B}$ between $\mathrm{SBP}$ and uninfected patients. Ascitic C3 concentrations were higher in patients without SBP than in infected patients $(0.37 v 0.08 \mathrm{~g} / \mathrm{l}, \mathrm{p}<0.05)$, as were factor $B$ values $(0.11 v 0.03 \mathrm{~g} / \mathrm{l}, \mathrm{p}<0.05)$. There was no significant difference in ascitic C4 concentrations in patients with SBP compared with uninfected patients $(0.03 v 0.07 \mathrm{~g} / \mathrm{l})$. Although consumption of $\mathbf{C} 3$, as shown by C3d/C3 in ascites, was increased in infected patients compared with uninfected patients $(79.1 v 36.1, \mathrm{p}<0.05)$, there was no difference in ascitic complement activation between the groups for either the classical or alternative pathways. In SBP, decreased plasma C3 and $\mathrm{C} 4$ are primarily caused by increased activation of the classical pathway and not impaired hepatic synthesis. Activation and consumption of $\mathrm{C} 3$ is one factor causing the low ascitic C3 concentrations observed in SBP.
\end{abstract}

A decrease in the circulating complement concentrations is seen in severe chronic liver disease and is thought to be one factor that predisposes to the high incidence of infection in patients with cirrhosis. ${ }^{1}$ One common infection in cirrhotic patients with ascites - spontaneous bacterial peritonitis (SBP) - is seen in approximately $25 \%$ during each admission to hospital, ${ }^{2}$ and has a mortality of up to $50 \% .^{3}$ Patients who develop SBP have impaired opsonic and bactericidal activity in the ascitic fluid both before and during infection, reflecting low $\mathrm{C} 3$ and $\mathrm{C} 4$ concentrations in the ascites. ${ }^{45}$ Low complement activity in the plasma and ascites of patients with severe liver disease could be secondary to a number of factors, including impaired synthesis by the liver, complement activation secondary to the primary disease process in addition to supervening infection, or altered clearance of complement from plasma.

This study aimed to examine the state of
TABLE I Clinical characteristics of patients with and without spontaneous bacterial peritonitis $(S B P)$ (values, median (range))

\begin{tabular}{lll}
\hline & $S B P$ & No SBP \\
\hline Age $(\mathrm{yrs})$ & 54 & 54 \\
Sex $(\mathrm{M} / \mathrm{F})$ & $(23-64)$ & $(27-69)$ \\
Survival $(\%)$ & $6 / 5$ & $11 / 10$ \\
$\quad(6$ weeks after admission) & $4(36)$ & $15(71)$ \\
Serum bilirubin & 183 & 71 \\
$\quad(\mu \mathrm{mol} / \mathrm{l})$ & $(49-527)$ & $(7-564)$ \\
Serum albumin & 28 & 29 \\
$\quad(\mathrm{~g} / \mathrm{l})$ & $(18-32)$ & $(18-43)$ \\
Prothrombin time & 26 & $18 \cdot 5$ \\
$(\mathrm{~s})$ & $(13-46)$ & $(13-40)$ \\
Ascitic protein & 9 & 12 \\
$(\mathrm{~g} / \mathrm{l})$ & $(6-34)$ & $(9-31)$ \\
\hline
\end{tabular}

activation of the complement system in the plasma and ascites of patients with severe liver disease in the presence or absence of SBP, to determine whether complement activation and consumption or decreased synthesis contributes to the low values previously observed in the ascites of patients with severe chronic liver disease.

\section{Methods}

Thirty two patients with ascites secondary to severe chronic liver disease were included in the study (Table I). Plasma and ascites were taken from 11 patients with SBP (five women and six men) as defined by the presence in ascites of $>250$ neutrophils $/ \mathrm{mm}^{3}$ or positive bacterial or fungal cultures. Of the patients with SBP, six had alcoholic cirrhosis, three cirrhosis secondary to chronic non-A, non-B infection, one had cirrhosis secondary to chronic hepatitis B infection, and one primary biliary cirrhosis. Plasma and ascites were also taken from 21 uninfected patients ( 10 women and $11 \mathrm{men}$ ). In both groups at the time the samples were taken there was no evidence of infection at other sites and none of the patients were on antibiotic treatment. Nineteen of these patients had cirrhosis ( 15 secondary to alcoholic liver disease, two secondary to chronic non-A, non-B infection, one halothane hepatitis superimposed on alcoholic cirrhosis, and one haemochromatosis). One patient had non-cirrhotic portal hypertension and one had chronic Budd-Chiari syndrome. Patients were graded according to Pugh's modification of the Child's classification (Table II). ${ }^{6}$

Ascitic fluid was obtained within five days of admission using a sterile technique, and samples for culture and microscopy were collected in sterile glass bottles. Additional samples for microbiology were cultured in blood culture bottles by the Bactec system (Becton Dickinson and Company, Towson, Md, USA). ${ }^{7}$ Ascites for estimation of complement was collected in 
EDTA (to a final concentration of $10 \mathrm{mmol} / \mathrm{l}$ ) onto ice and spun down at $4^{\circ} \mathrm{C}$. The supernatant was stored immediately in liquid nitrogen until assayed. At the same time blood samples for estimation of complement were collected and centrifuged and the plasma stored similarly.

For comparison, blood was taken for complement estimation from 19 healthy subjects (11 men and eight women, median age 30 years, range $20-58$ ).

\section{C3, C4, AND FACTOR B MEASUREMENT}

Plasma and ascitic concentrations of $\mathrm{C} 3, \mathrm{C} 4$, and factor $\mathrm{B}$ were determined by laser nephelometry, using specific antisera to $\mathrm{C} 3$ and $\mathrm{C} 4$ (Behring Diagnostics, Middx, UK) and factor B (Dakopatts, High Wycombe, UK), according to the manufacturers' instructions. Results are expressed in $\mathrm{g} / \mathrm{l}$.

\section{C3D, C4D, AND BA MEASUREMENT}

The C3d concentrations were determined by a nephelometric technique. ${ }^{8}$ Briefly, plasma or ascites was brought to $11 \%$ final concentration of polyethylene glycol 6000 (Sigma Chemicals, Poole, UK) and centrifuged at $1500 \mathrm{~g}$ for 30 minutes at $4^{\circ} \mathrm{C}$. This manoeuvre precipitates $\mathrm{C} 3$ and its larger fragments, leaving $\mathrm{C} 3 \mathrm{~d}$ in the supernatant. The concentration of $\mathrm{C} 3 \mathrm{~d}$ was then measured by laser nephelometry, using anti-C3d antiserum (Dakopatts). The C4d and Ba concentrations were measured similarly using anti-C4 intact antiserum (Behring Diagnostics) and antifactor B antiserum (Dakopatts) after treatment of the plasma or ascites samples with high polyethylene glycol concentrations. ${ }^{910} \mathrm{C} 3 \mathrm{~d}$ and C4d results were expressed as percentages of $100 \% \mathrm{C} 3 \mathrm{~d}$ and C4d standards, obtained by exhaustively activating complement through the classical pathway by incubating normal human serum with heat aggregated immunoglobulin. Ba results were expressed as percentages of a $100 \%$ Ba standard, obtained by exhaustively activating the alternative complement pathway by incubating normal human serum with inulin. Since the initial concentration of intact complement components may influence the concentrations of their fragments, the $\mathrm{C} 3 \mathrm{~d} / \mathrm{C} 3, \mathrm{C} 4 \mathrm{~d} / \mathrm{C} 4$, and $\mathrm{Ba} /$ factor $B$ ratios were calculated to obtain indices of complement activation (complement activation ratios) on all samples of plasma and ascites. The $\mathrm{C} 3 \mathrm{~d} / \mathrm{C} 3$ and $\mathrm{C} 4 \mathrm{~d} / \mathrm{C} 4$ ratios have been shown to correlate positively with the in vivo fractional catabolic rate of $\mathrm{C} 3$ and $\mathrm{C} 4 .{ }^{11} 12$

Group data are expressed as mean values with 95\% confidence intervals $(\mathrm{CI})$ and complement activation ratios as mean (SEM). Comparison of group data was also performed using the Wilcoxon rank sum test and a value of less than 0.05 considered significant.

\section{Results}

PLASMA C3, C4, FACTOR B

Plasma C3 concentrations were significantly reduced in patients with $\mathrm{SBP}(0.74 \mathrm{~g} / \mathrm{l} ; \mathrm{CI}, 0.56$ to 0.92 ) compared with uninfected patients
$(1 \cdot 13 \mathrm{~g} / \mathrm{l} ; \mathrm{CI}, 0.95$ to $1 \cdot 31 ; \mathrm{p}<0.01)$ and normal controls $(0.88 \mathrm{~g} / \mathrm{l} ; \mathrm{CI}, 0.82$ to $0.94 ; \mathrm{p}<0.05)$ (Fig 1A). Plasma C4 $(0 \cdot 20 \mathrm{~g} / \mathrm{l} ; \mathrm{CI}, 0 \cdot 16$ to $1 \cdot 24)$ was also reduced when compared with uninfected patients $(0.28 \mathrm{~g} / \mathrm{l} ; \mathrm{CI}, \mathbf{0 . 2 0}$ to $0.36 ; \mathrm{p}<0.05)$, but not when compared with normal controls $(0 \cdot 21$ $\mathrm{g} / \mathrm{l} ; \mathrm{CI}, 0 \cdot 17$ to $0 \cdot 25$ ) (Fig 1B). The plasma factor $\mathrm{B}$ concentration in SBP patients $(0 \cdot 19 \mathrm{~g} / \mathrm{l} ; \mathrm{CI}$, 0.15 to 0.23 ) was not significantly different from that in patients without $\operatorname{SBP}(0 \cdot 24 \mathrm{~g} / \mathrm{l} ; \mathrm{CI}, 0.20$ to $0 \cdot 28)$ or controls $(0.18 \mathrm{~g} / \mathrm{l} ; \mathrm{CI}, 0 \cdot 16$ to 0.20$)$ (Fig 1C). In uninfected patients compared with controls, there was no significant difference in plasma $\mathrm{C} 3$ and $\mathrm{C} 4$ but there was a statistically significant $(p<0.01)$ increase in plasma factor $B$ in these patients (Fig 1C).

PLASMA COMPLEMENT ACTIVATION INDICES Calculation of activation ratios showed that plasma C3 activation was significantly greater in patients with SBP $(14.0(1 \cdot 71))$ than in normal subjects $(6.28(0.53))$ and patients without SBP
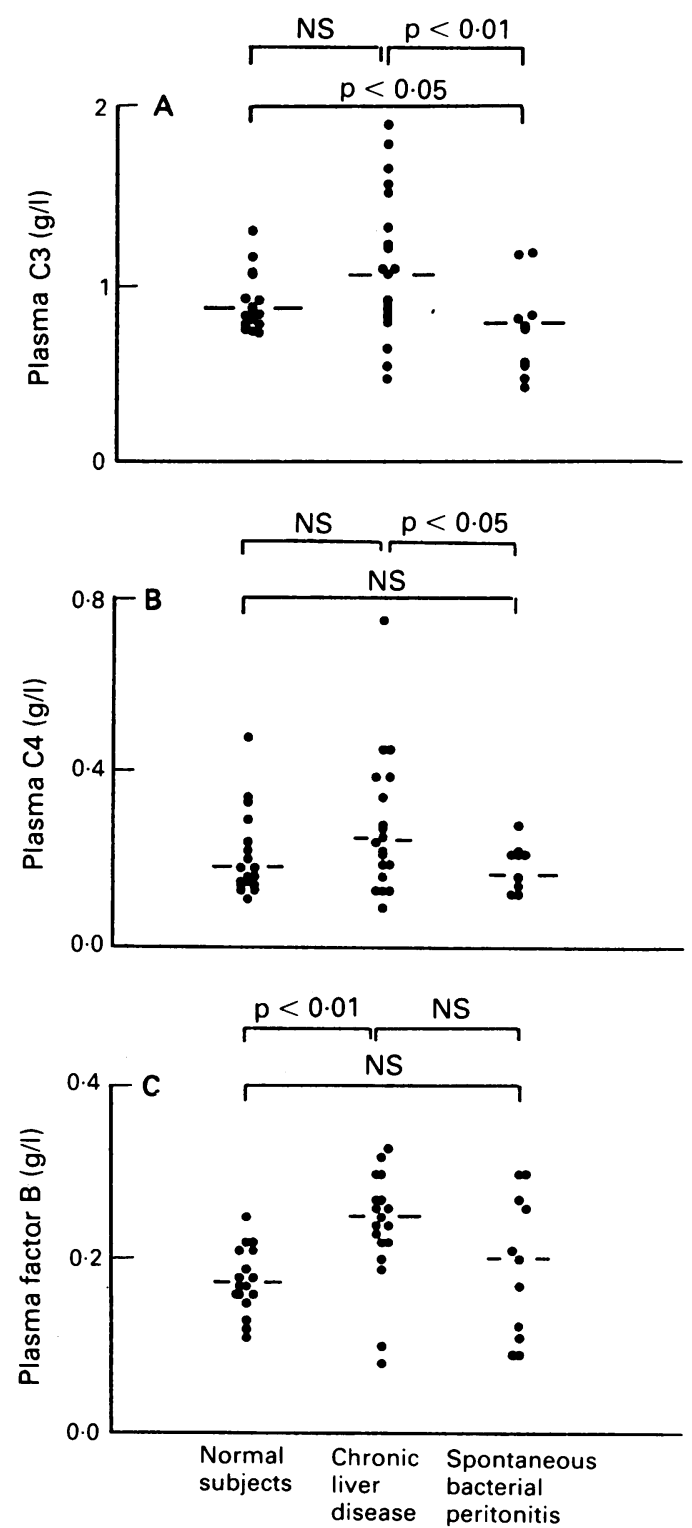

Figure 1: $C 3(A), C 4(B)$, and factor $B(C)$ in plasma of patients with spontaneous bacterial peritonitis, patients with severe chronic liver disease without infection, and normal subjects. 

Figure 2: Complement
activation as indicated by $C 3 d / C 3(A), C 4 d / C 4(B)$, and $B$ alfactor $B(C)$ in plasma of patients with spontaneous bacterial peritonitis, patients with severe chronic liver disease without infection, and normal subjects.
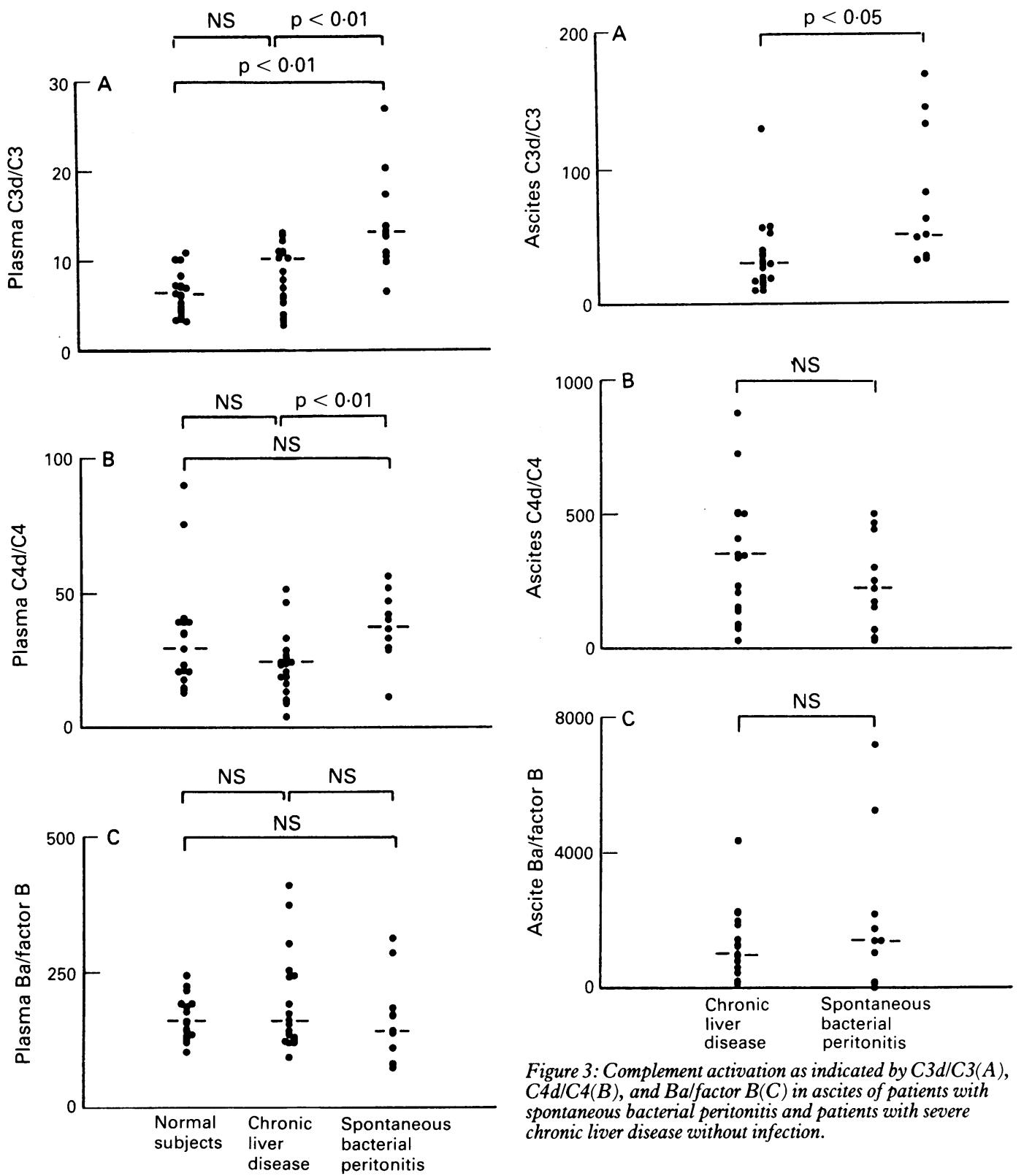

Figure 3: Complement activation as indicated by $C 3 d / C 3(A)$, $C 4 d / C 4(B)$, and Balfactor $B(C)$ in ascites of patients with spontaneous bacterial peritonitis and patients with severe chronic liver disease without infection.

$(8 \cdot 11(0 \cdot 70))(\mathrm{p}<0 \cdot 01)($ Fig 2A). Plasma C4 activation was also greater in SBP patients than in uninfected patients $(37 \cdot 3(4 \cdot 1)$ v $22 \cdot 2(2 \cdot 6)$, $\mathrm{p}<0.01$ ), but there was no significant difference between SBP patients and normal controls (33.0 (4.6)) (Fig 2B). There was no significant difference in plasma factor $B$ activation between SBP patients $(168(25 \cdot 0))$ and patients without SBP $(195(21 \cdot 7))$ or normal controls $(166(10 \cdot 2))$ (Fig 2C).

Patients without SBP showed no significant difference from normal controls for activation of C3, C4, or factor B (Fig 2A-C).

ASCITES C3, C4, AND FACTOR B

Ascitic concentrations of both $\mathrm{C} 3$ and factor $\mathrm{B}$ were higher in patients without SBP $(0.37 \mathrm{~g} / \mathrm{l}$; CI, 0.23 to 0.51 and $0.11 \mathrm{~g} / \mathrm{l} ; \mathrm{CI}, 0.05$ to 0.17 respectively) than in patients with $\operatorname{SBP}(0.08 \mathrm{~g} / \mathrm{l}$; CI, 0.06 to 0.10 and $0.03 \mathrm{~g} / \mathrm{l} ; \mathrm{CI}, 0.01$ to 0.05 respectively, $\mathrm{p}<0.05)$. There was no significant difference in the ascitic concentrations of $\mathrm{C} 4$ $(0.07 \mathrm{~g} / \mathrm{l} ; \mathrm{CI}, 0.01$ to 0.13 and $0.03 \mathrm{~g} / \mathrm{l}, \mathrm{CI}, 0.01$ to 0.05 respectively).

\section{ASCITES COMPLEMENT ACTIVATION INDICES}

Calculation of activation ratios showed that ascitic $\mathrm{C} 3$ activation was significantly greater in infected patients $(36 \cdot 1(6 \cdot 35), \mathrm{p}<0 \cdot 05)$ (Fig 3A). When patients with SBP were compared with uninfected patients, this difference was not present for ascitic C4 activation $(241(51 \cdot 4) v 336$ $(54 \cdot 4))$ (Fig 3B) or ascitic factor B activation (2140 (724) $v 1220(240)$ ) (Fig 3C).

Clinical grading of the patients by the Pugh's classification showed no significant differences in the severity of the liver disease between patients with SBP and those without infection (Table II). Seven of the patients with SBP died during the course of their admission, although in only four $(36 \%)$ was death attributable to SBP. Six $(29 \%)$ of the patients without evidence of SBP died.

\section{Discussion}

This study shows that the low C3 concentrations found in plasma and ascites of patients with SBP are consistent with increased complement activation rather than decreased hepatic synthesis. patients with SBP $(79 \cdot 1(16 \cdot 39))$ than in un- 
Low plasma $\mathrm{C} 3$ and $\mathrm{C} 4$ concentrations in patients with SBP are caused by activation by the classical pathway, as indicated by the increase in the respective activation ratios with no change in the activation ratio of factor $B$ in either infected or uninfected patients. In this study, plasma C 3 and $\mathrm{C} 4$ concentrations in patients without SBP were not significantly different from those in normal control subjects. In patients with SBP, significant activation of $\mathrm{C} 3$ in ascites was also shown but not activation of $\mathrm{C} 4$ or factor B. Factors triggering classical pathway activation in patients with SBP could include IgM and IgG complexes. Our results do not support the possibility that significant alternative pathway activation, for example from endotoxin, is taking place.

These findings are compatible with those of previous studies which showed normal or reduced $\mathrm{C} 3$ concentrations in patients with chronic liver disease. ${ }^{13-16}$ Although details of whether infection was present were not given, the decrease was generally less noticeable in patients with alcoholic liver disease than in those with liver diseases of other aetiologies. ${ }^{14} 16$ Since, in the present study, most patients had alcoholic cirrhosis with superimposed alcoholic hepatitis, it is possible that the finding of increased plasma C3, C4, and factor B concentrations in a number of subjects without SBP could be secondary to increased synthesis as part of the acute phase response in patients with alcoholic hepatitis. It is of interest that although all our patients had severely decompensated liver disease with poor synthetic function as judged by low serum albumin and prolonged prothrombin time, hepatic synthesis of $\mathrm{C} 3, \mathrm{C} 4$, and factor B was not impaired. This finding contrasts with early studies which compared reduced complement concentrations with impaired synthetic function and showed a positive correlation. ${ }^{16} 17$

In two recent studies, patients with low ascitic C3 concentrations were shown to be more likely to develop SBP while in hospital, although a similar relation between C4 and SBP was not present. ${ }^{518}$ However, in both studies the patients in whom SBP later developed had more severe liver disease as judged by Child's grading, and the increased likelihood of developing SBP could have been a reflection of the severity of underlying liver disease. In the present study, infection was already present when the ascites in which complement concentrations were measured was obtained - it is therefore possible that the presence of infection could have worsened the abnormalities in the prothrombin time and serum bilirubin, which are included as factors in Child's grading of severity of disease, and this would have made it less likely that our patients with SBP had more severe underlying liver disease.

A further consideration is the possible effect that diuresis and paracentesis could have on the complement concentrations in ascites. Runyon et al reported that complement activity in the serum and ascites of patients undergoing diuretic treatment alone was higher than in patients in whom repeated paracenteses were performed. ${ }^{19}$ In the present study, samples were obtained before therapeutic paracentesis was performed.
Nevertheless, it is possible that the effects of diuretics on the patients could have influenced the results. Similarly, it is possible that the contrast between plasma and ascites complement concentrations could be influenced by the effect of infection on the permeability of peritoneal capillaries. In the study by Such, however, a direct correlation between serum $\mathrm{C} 3$ and ascitic fluid C3 was observed. It is of interest that in Such's study the ascitic fluid protein was significantly less in the patients who developed SBP, a feature also present in the patients reported here, even although by Child's grading the underlying liver disease was of similar severity and there was no difference in the serum albumin concentrations in the infected and uninfected patients (Table I). ${ }^{5}$

In common with other recent studies, the possible effect of decreased hepatic clearance on complement components has not been taken into account. ${ }^{45}$ However, animal models suggest that complement catabolism takes place in other organs such as the lung, spleen, and kidney and it is therefore unlikely that impaired hepatic clearance would cause a rise in plasma complement fragment values. ${ }^{20}$

In patients without SBP compared with normal controls, complement activation showed no significant differences. This argues against a mechanism whereby complement activation is involved in the pathogenesis of the underlying liver disease, although this has been suggested as a possible mechanism of cell damage in alcoholic liver disease. ${ }^{21}$ However, it is possible that in our severely decompensated patients there was little continuing hepatocellular damage and clues as to the pathogenesis may not be present.

These findings suggest that the decrease in plasma complement values present in advanced liver disease could be indicative of infection and are unlikely to be affected by impaired synthetic capacity of the liver. Our findings also show that SBP is accompanied by activation of the classical complement pathway in plasma, highlighting the systemic nature of the infection and underline the results of previous studies which have shown that patients with a low ascitic protein are at highest risk of developing SBP.

Dr G Senaldi was supported by a grant from the Royal Society of Medicine. Part of this study has already been published in abstract form.

1 Rajkovic IA, Williams R. Mechanisms of abnormalities in host defences against bacterial infection in liver disease. Clin Sci 1985; 68: 247-53.

2 Pinzello G, Simonetti RG, Craxi A, Di Piazza S, Spano C, Pagliaro L. Spontaneous bacterial peritonitis: a prospective investigation in predominantly nonalcoholic patients. Hepatology 1983; 3: 545-9.

3 Tito L, Rimola A, Gines P, Llach J, Arroyo V, Rodes J. Recurrence of spontaneous bacterial peritonitis in cirrhosis: frequency and predictive factors. Hepatology 1988; 8: 27-31.

4 Runyon BA. Patients with deficient ascitic fluid opsonic activity are predisposed to spontaneous bacterial peritonitis. Hepatology 1988; 8: 632-5.

5 Such J, Guarner C, Enriquez J, Rodriguez JL, Seres I, Vilardell F. Low C3 in cirrhotic ascites predisposes to Vilardell F. Low C3 in cirrhotic ascites predisposes to
spontaneous bacterial peritonitis. F Hepatol $1988 ; 6: 80-4$. 6 Pugh RNH, Murray-Lyon IM, Dawson JL. Transection of the oesophagous for bleeding oesophageal varices. $B r \mathcal{F}$ Surg
the 1973; 60: 646-9.

7 Runyon BA, Canawati HN, Akriviadis EA. Optimisation of ascitic fluid culture technique. Gastroenterology 1988; 95: 1351-5.

8 Vergani D, Bevis L, Nasaruddin BA, Mieli-Vergani G, Tee D. Clinical application of a new laser nephelometric technique to measure complement activation. $\mathcal{F}$ Clin Pathol 1983; 6: 793-9. 
9 Davies ET, Nasaruddin BA, Alhaq A, Senaldi G, Vergani D. Clinical application of a new technique measuring C4d for
the assessment of activation of the classical complement the assessment of activation of the classic
pathway. $\mathcal{C}$ Clin Pathol 1988; 41: 143-7.

10 Senaldi G, Peakman M, Alhaq A, Makinde VA, Tee DEH, Vergani $D$. Activation of the alternative complement pathway: clinical application of a new technique to measure fragment Ba. $\mathcal{F}$ Clin Pathol 1987; 40: 1235-9.

11 Swaak AJ, Van Rooyen A, Vogelaar C, Pillay M, Hack E. Complement (C3) metabolism in systemic lupus erythematosus in relation to the disease course. Rheumatol Int 1986; 6 ; $221-6$.

12 Milgrom H, Curd JG, Kaplan RA, Muller-Eberhard HJ, Vaughn JH. Activation of the fourth component of complement (C4): assessment by rocket immunoelectrophoresis ment (C4): assessment by rocket immunoelectrophoresis 124: $2780-5$.

13 Fox RA, Dudley FJ, Sherlock $S$. The serum concentration of the third component of complement B1C-B1A in liver disease. Gut 1971; 12: 574-8.

14 Thompson RA, Carter R, Stokes RP, Geddes AM, Goodall JAD. Serum immunoglobulins, complement component levels and autoantibodies in liver disease. Clin Exp Immunol 1973; 14: 335-46.
15 Finlayson NDC, Krohn K, Fauconnet MH, Anderson KE. Significance of serum complement levels in chronic liver Significance of serum complement levels
disease. Gastroenterology 1972; 63: 653-8.

16 Kourilsky O, Leroy C, Peltier AP. Complement and liver cell function in 53 patients with liver disease. Am $\mathcal{F}$ Med 1973; 55: 783-90

17 Munoz LE, De Villiers D, Markham D, Whaley K, Thomas HC. Complement activation in chronic liver disease. Clin Exp Immunol 1982; 47: 548-54

18 Mal F, Pham Huu T, Bendahou M, Trinchet JC, Garnier M, Hakim J, et al. Chemoattractant and opsonic activity in ascitic fluid: a study in 47 patients with cirrhosis or malignant peritonitis. $\mathcal{F}$ Hepatol 1991; 12: 45-9.

19 Runyon BA, Antillon MR, Montano AA. Effect of diuresis versus therapeutic paracentesis on ascitic fluid opsonic activity and serum complement. Gastroenterology 1989; 97: activity and $158-62$.

20 Webster RO, Larsen GL, Henson PM. In vivo clearance and tissue distribution of $\mathrm{C} 5 \mathrm{a}$ and $\mathrm{C} 5 \mathrm{a}$ des arginine complement fragments in rabbits. $\mathcal{F}$ Clin Invest 1982; 70: 1177-83.

21 Barry RE, McGiven JD. Acetaldehyde alone may initiate hepatocellular damage in acute alcoholic liver disease. Gut 1985; 26: 1065-9. 